\title{
Minimizing the thermal bridge through the columns in a refrigeration room
}

\author{
Xiaoqiang Jiang ${ }^{\mathrm{a}, *}$, Aqiang Lin ${ }^{\mathrm{b}}$, Hailing $\mathrm{Ma}^{\mathrm{c}}$, Xingyou $\mathrm{Li}^{\mathrm{a}}$, Yiyu $\mathrm{Li}^{\mathrm{a}}$ \\ ${ }^{a}$ School of Ecological Environment and Urban Construction, Fujian University of Technology, Fuzhou 350118, China \\ ${ }^{\mathrm{b}}$ College of Power and Energy Engineering, Harbin Engineering University, Harbin 150001, China \\ ${ }^{\mathrm{c}}$ Institute of Mechanics, Chinese Academy of Sciences, Beijing 100190, China
}

\section{H I G H L I G H T S}

- Thermal bridges of the column are numerically simulated in the refrigeration room.

- Contribution shares of reinforcement concrete in the column on the cooling loss are discussed.

- Optimization method of energy-saving heat preservation is proposed to minimize the cooling loss.

\section{A R T I C L E I N F O}

\section{Keywords:}

Refrigeration room

Thermal bridge

Cooling loss

Column

Heat preservation

\begin{abstract}
A B S T R A C T
Thermal bridges are weakly insulated areas in the envelope of a building that can significantly increase the energy load due to heat dissipation. To improve energy efficiency, a thermal bridge model is established to simulate heat transfer through the column in a refrigeration room. The accuracy of the numerical simulation program is verified by experimental data. A heat preservation method for the column that minimizes the cooling loss is analyzed. The results show that the thermal bridging is mainly due to the steel bar in the column, because the share of the cooling loss attributed to the steel bars is 42.02-55.87\%. Moreover, applying heat insulation on the column can provide more energy savings in low-temperature rooms than in high-temperature ones. The most economical thermal insulation method as a function of the height and thickness of the insulation layer is therefore proposed for the low-temperature column. By the optimum method, the amount of heat flux through the whole column section, which includes both reinforced and non-reinforced areas, decreases by $37.34 \%$, and the total cooling loss decreases from 30.23 to $13.66 \mathrm{~W}$, representing a $54.81 \%$ reduction. Therefore, a reduction in the cooling loss from thermal bridging is achieved for a low-temperature refrigeration room.
\end{abstract}

\section{Introduction}

In recent years, the use of refrigeration has increased tremendously with the promotion of global cold chain commodity markets, the fresh food industry and the Internet economy [1,2]. Refrigeration is one of the most energy-intensive technologies used in the food supply chain $[3,4]$, and it accounts for about $35 \%$ of the electricity consumption in the food industry [5], Moreover, energy is a major cost in cold food storage operations $[6,7]$. Energy saving methods for refrigeration rooms are thus a promising area for technological development.

There are many elements in refrigeration rooms that can form a thermal bridge, resulting in a loss of heat or cold that increases the building's energy consumption [8-11]. Hao et al. [12] simulated velocity and temperature fields using the finite volume method with the standard $k-\varepsilon$ turbulence equation. Hoang et al. [13] studied the airflow and heat transfer in a cold room filled with apple pallets. Carneiro et al.
[14] developed 3D CFD modeling of the opening/closing cycle of cold room doors. They found that the air infiltration rate through a sliding door was $20 \%$ lower than through a hinged one and the air temperature inside a cold room with a sliding door was $17 \%$ lower than that of the hinged one. Tian et al. [15] developed an unsteady analytical model for predicting the infiltration flow rate through the doorways of refrigerated rooms. Other scholars have studied the effect of thermal bridges on a building's energy efficiency. Freitas et al. [16] found that it was necessary to consider the roles of thermal bridges since this factor is of great importance for thermal comfort and energy consumption. AlSanea and Zedan [17] investigated the thermal bridges caused by mortar joints cutting across the insulation layers within building walls. They recommended that the effects due to mortar joints should be reduced, since thermal bridges result in a higher inner surface temperature and transmission load fluctuations. Baldinelli et al. [18] developed a mathematical algorithm to enhance the image resolution and

\footnotetext{
* Corresponding author.

E-mail address: jiangxq@fjut.edu.cn (X. Jiang).
} 
accuracy of the energy loss assessment in thermal bridging, which could provide an improvement in accuracy of up to $2 \%$ of the total building envelope energy losses.

The computational fluid dynamics (CFD) approach is often used to study load temperature distribution [19,20]. Smale et al. [21] and Lin et al. [22] emphasized the complementary roles played by CFD analysis and experimental studies. Ascione et al. [23] performed a numerical analysis of thin-film heat flux sensors for the resolution of thermal bridges, which was validated through comparison with experimental data. They revealed very satisfactory results in terms of reliability and accuracy. O'Grady et al. [24] numerically and experimentally investigated thermal bridging heat loss using a typical L-shaped thermal bridge. They found that heat loss from a building surface is significantly influenced by wind velocity. Ibrahim et al. [25] numerically presented an innovative insulation coating to limit thermal bridge effects and found that applying the coating reduces the window's offset thermal bridge load by about $24-50 \%$. Prata et al. [26] evaluated the dynamic thermal behavior of a linear thermal bridge in the corner of a wooden building. Results show that the amplitudes of the internal surface temperature and the heat fluxes are greater after thermal insulation. Hence, various insulation materials [27-29] and optimization strategies $[30,31]$ are proposed to decrease thermal bridging.

As discussed above, thermal bridges are of great importance for energy consumption. However, few studies have reported on the contribution of thermal bridging through columns to the cooling loss and temperature fluctuation in a refrigeration room. The existence of thermal bridges causes a large amount of heat to enter the refrigeration room, which results in temperature fluctuations and increases energy consumption. Simultaneously, since the columns cross multiple temperature regions, the columns become the most significant thermal bridge in the refrigeration room and cause significant amounts of cooling loss. Research on heat preservation in columns is therefore of significance. This study is concerned with minimizing thermal bridging through the columns in a refrigeration room to reduce energy consumption. A thermal bridge model in a refrigeration room is proposed to simulate the thermal transfer process through the columns. The effect of heat transfer through the thermal bridge is analyzed, and the addition of heat preservation on the column is compared with no additional heat preservation on the column. Based on a comprehensive approach that considers reduction of both heat transfer and the amount of heat insulating material, an optimal energy-saving insulation method is proposed.

The remainder of this study is organized as follows: in Section 2, the physical model and governing equations are modeled and experimentally validated in low- and high-temperature refrigeration rooms; in Section 3, the heat transfer of the thermal bridge with and without consideration of the column insulation will be described, and the results of the economic analysis of the case study are presented; and finally in Section 4, some of the conclusions that can be derived from this study are summarized.

\section{Model and method}

\subsection{Description of the building model}

As the main place for processing and storing frozen food, a refrigeration room has the characteristics of a large load and high temperature difference between the inside and outside. For a refrigeration room with multi-storey cold storage, the columns in the refrigeration room will pass through the soil, the floor, the high-temperature refrigeration room (HTRR), the low-temperature refrigeration room (LTRR), and the roof respectively, as illustrated in Fig. 1. (Many of these cold storage spaces exist in southern China.) Obviously, the reinforcement bars in the columns will form a thermal bridge, that is, many thermal bridges are created by the extensive use of reinforcement bars in cold storage buildings. Since heat can easily transfer from the high- temperature to low-temperature regions, this phenomenon will increase the cooling load due to temperature variations in the refrigeration room and will also affect the quality of the stored food.

Cold storage generally consists of a low-temperature refrigeration room (LTRR) and a high-temperature refrigeration room (HTRR). The LTRR design temperature is about $T_{a}=-18^{\circ} \mathrm{C}$ for storing meat. The HTRR design temperature is in the $T_{b}=0-5{ }^{\circ} \mathrm{C}$ range $\left(T_{b}=2{ }^{\circ} \mathrm{C}\right.$ in this study), which is mainly used for storing fruit, vegetables, and similar items. If the LTRR is placed directly on the ground, it may cause the soil under the floor to freeze and heave due to the low temperature, resulting in damage to the refrigeration room structure. For a typical multi-level refrigeration room as shown in Fig. 1, the HTRR is on the first floor below the LTRR. Columns that are $10.25 \mathrm{~m}$ in length pass through the LTRR and HTRR, which are $5 \mathrm{~m}$ in height in total for both the upper and lower levels of the refrigeration rooms and $0.25 \mathrm{~m}$ thickness in the floor layer. The cross-sectional dimensions of the column are $0.5 \times 0.5 \mathrm{~m}$. The floor slab consists of a 0.15 -meter reinforced concrete layer on the HTRR side and a 0.1-meter insulation layer on the LTRR side. The cross-sectional dimensions of the slab are $6 \times 6 \mathrm{~m}$, that is, the distance between the columns is $6 \mathrm{~m}$. Twelve steel bars that are $25 \mathrm{~mm}$ in diameter are arranged in the reinforced concrete, but the hoop steel bars are ignored. The proportional area of the steel bars is $2.36 \%$ of the total cross-sectional area of the column.

\subsection{Simulation model}

The steel bars existing within the columns will form a thermal bridge, and the thermal balance leads to heat transfer from the HTRR into the LTRR. This phenomenon is the main reason for the increase in cooling load and energy consumption in the LTRR. To meet the needs of a good engineering practice, the computational model includes the column with the steel bars and concrete, floor slab and insulation layer. The simplified geometry and arrangement are shown in Fig. 1.

Since the columns made up of steel bars and reinforced concrete are in contact with the floor and insulation material, the convection heat transfer, heat conduction, and multiple boundary conditions of the thermal bridge should be considered in the refrigeration room. The governing equations for the thermal bridge under steady-state conditions can be established as:

$\frac{\partial^{2} T_{m}}{\partial x^{2}}+\frac{\partial^{2} T_{m}}{\partial y^{2}}+\frac{\partial^{2} T_{m}}{\partial z^{2}}=0, \quad m=1,2,3,4$

where $\mathrm{x}, y$, and $z$ are in the Cartesian coordinates, $T$ is the temperature, and the subscripts $m=1,2,3,4$ represent the material categories of the floor layer, insulation layer (polystyrene), column (reinforced concrete) and steel bar (steel), respectively. Here, different material attributes are shown in Table 1.The thermal conductivity of polystyrene has been corrected to $\lambda=0.0611 \mathrm{~W} \cdot(\mathrm{m} \mathrm{K})^{-1}$, starting from a theoretical value of $\lambda=0.047 \mathrm{~W} \cdot(\mathrm{m} \mathrm{K})^{-1}$, to account for the very low temperature, as suggested by the Chinese Code for the Design of Cold Stores [32].

Since the inner wall temperature of the refrigeration room is close to the indoor air temperature (no windows in the room), radiation heat transfer can be neglected in this case. Thus, the thermal bridge model can be obtained by Eqs. (2) and (3) for between the HTRR and the column, Eqs. (4) and (5) for between the LTRR and the column, Eq. (6) for between the HTRR air and the floor layer, Eq. (7) for between the LTRR air and the floor layer, and Eq. (8) for between the steel bars and the column, as follows:

$$
\begin{aligned}
& -\lambda_{3} \frac{\partial T_{3}}{\partial x}=\alpha_{\mathrm{b}}\left(T_{3}-T_{\mathrm{b}}\right) \\
& -\lambda_{3} \frac{\partial T_{3}}{\partial \mathrm{y}}=\alpha_{\mathrm{b}}\left(T_{3}-T_{\mathrm{b}}\right) \\
& -\lambda_{3} \frac{\partial T_{3}}{\partial x}=\alpha_{\mathrm{a}}\left(T_{3}-T_{\mathrm{a}}\right)
\end{aligned}
$$




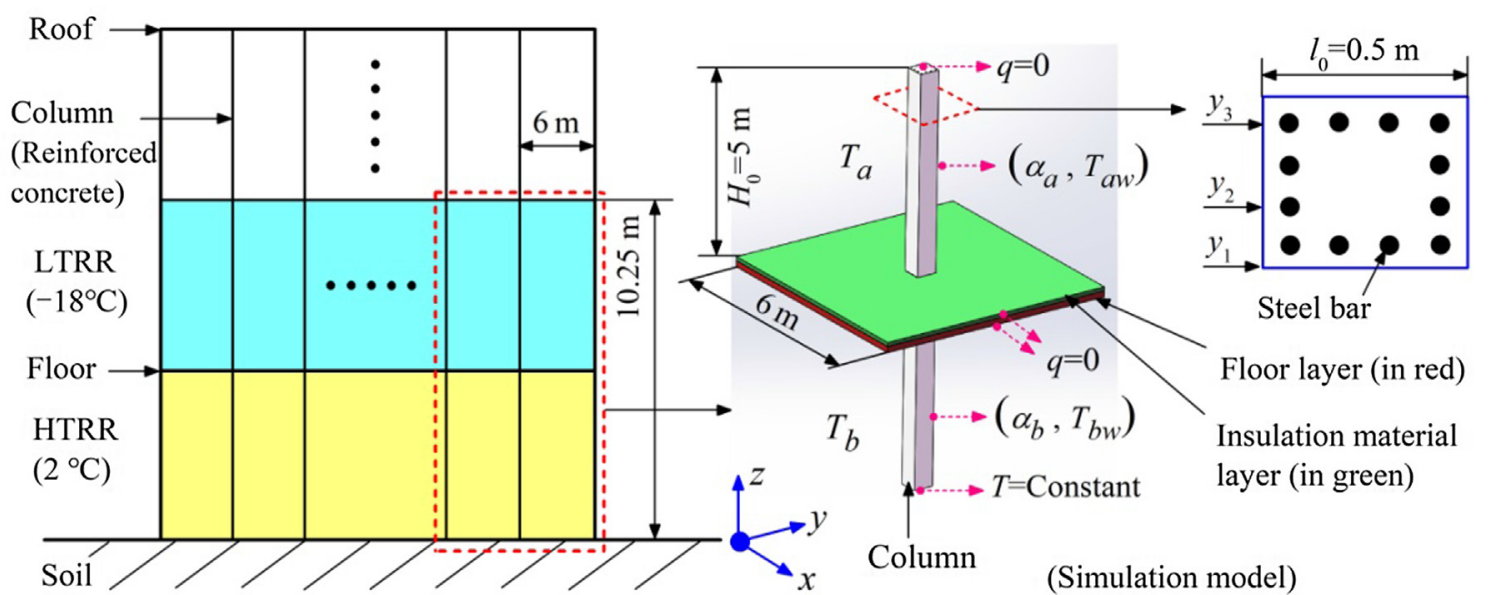

Fig. 1. Schematic diagram of the multi-level refrigeration room including the simulation model and details of the cross-section of the column.

Table 1

Physical property of different building materials according to the design code for cold storage.

\begin{tabular}{llll}
\hline Materials & $\begin{array}{l}\text { Thermal } \\
\text { conductivity } \\
\mathrm{W} \cdot(\mathrm{m} \cdot \mathrm{K})^{-1}\end{array}$ & $\begin{array}{l}\text { Specific heat } \\
\text { capacity } \\
\mathrm{kJ} \cdot(\mathrm{kg} \cdot \mathrm{K})^{-1}\end{array}$ & $\begin{array}{l}\text { Dry density } \\
\mathrm{kg} \cdot \mathrm{m}^{-3}\end{array}$ \\
\hline $\begin{array}{l}\text { Structural steel } \\
\text { Polystyrene }\end{array}$ & 58.2 & 0.48 & 7850 \\
Reinforced concrete & 0.0611 & 1.38 & 100 \\
& 1.74 & 0.92 & 2500 \\
\hline
\end{tabular}

$-\lambda_{3} \frac{\partial T_{3}}{\partial y}=\alpha_{\mathrm{a}}\left(T_{3}-T_{\mathrm{a}}\right)$

$-\lambda_{1}\left(\frac{\partial T_{1}}{\partial \mathrm{x}}+\frac{\partial T_{1}}{\partial \mathrm{y}}\right)=\alpha_{\mathrm{b}}\left(T_{3}-T_{b}\right)$

$-\lambda_{2}\left(\frac{\partial T_{2}}{\partial \mathrm{x}}+\frac{\partial T_{2}}{\partial \mathrm{y}}\right)=\alpha_{\mathrm{a}}\left(T_{2}-T_{a}\right)$

$\lambda_{3}\left(\frac{\partial T_{3}}{\partial x}+\frac{\partial T_{3}}{\partial y}+\frac{\partial T_{3}}{\partial z}\right)=\lambda_{4}\left(\frac{\partial T_{4}}{\partial x}+\frac{\partial T_{4}}{\partial y}+\frac{\partial T_{4}}{\partial z}\right)$

where the subscripts a and b correspond to the LTRR and HTRR locations, respectively, $\lambda$ is the thermal conductivity, and $\alpha$ is the convective heat transfer coefficient. In this case, the convective heat transfer coefficients of the envelope material for both the floor and the column [32] are determined to be $\alpha_{\mathrm{a}}=12 \mathrm{~W} \mathrm{~m}^{-2} \mathrm{~K}^{-1}$ and $\alpha_{\mathrm{b}}=18 \mathrm{~W} \mathrm{~m}^{-2} \mathrm{~K}^{-1}$, respectively, in the LTRR and HTRR.

Due to the symmetry of the building structure, the four sides of the floor slab and the top of the column are assigned as adiabatic walls. The temperature at the bottom of the column is assumed to be constant due to the surrounding soil. The geometry for the simulation model in Fig. 1 is created and meshed using the commercial Solidworks 2018 software. After the grid independence study, the number of unstructured grid cells is determined to be about 905,497 . Based on the Solidworks code, the thermal bridge is solved by a finite difference method under threedimensional steady-state conditions.

\subsection{Model validation}

Since the characteristics of thermal resistance involve a large measurement range of temperature, a platinum resistance AZ8821 type thermometer with $\pm 0.15{ }^{\circ} \mathrm{C}$ measurement accuracy and $-100 \sim 300^{\circ} \mathrm{C}$ measurement range was selected to measure the flow field temperature. The temperature was measured three times per point, and then we took the average value. Moreover, the measurement time for each measurement was more than $5 \mathrm{~min}$. (Here, the requirement for the response time in the thermometer specification was only $3 \mathrm{~min}$.)The errors in the temperature measurement system in this paper were mainly due to measurement errors, environmental errors and operational errors. The working temperature of the test instrumentation of the AZ 8821 was $0-50{ }^{\circ} \mathrm{C}$ while the ambient temperature was $-18^{\circ} \mathrm{C}$, which exceeded the preset working temperature, resulting in a systematic error. When the surface temperature of the column was measured, the platinum resistance probe did not fully contact the wall due to the large size of the probe, so it still had a large area of exposure to the air in the low-temperature cold room. This phenomenon would result in a lower temperature (the air temperature in the low-temperature cold room was lower than that on the surface of the column). Under the influence of these two errors, the error in the temperature measurement system was determined to be $1.18^{\circ} \mathrm{C}$ according to the error evaluation method [33].

To minimize the uncertainty caused by the error in the measurement system process, every temperature point was measured three times and the average value was taken. In addition, the temperature measurement was carried out under stationary conditions. A comparison between the simulation and test results of the heat transfer in the thermal bridge of the column in the refrigeration room was then conducted, as shown in Fig. 2. An error in the wall temperature can be seen between the experimental data and simulation result.

As evidenced in Fig. 2, the column surface temperature gradually decreases with the column height, and it is close to the air temperature

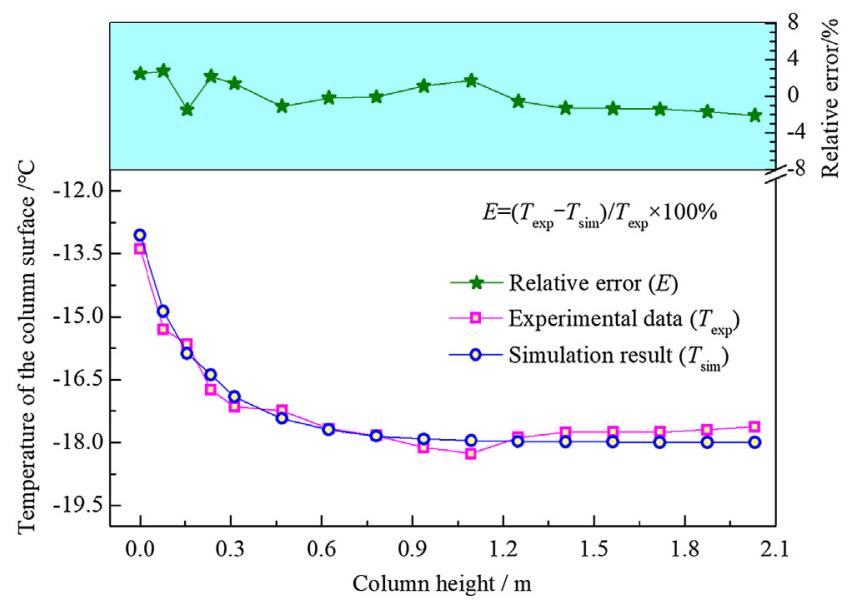

Fig. 2. Comparison between the experimental data and simulation results of the column wall temperature in the LTRR. 


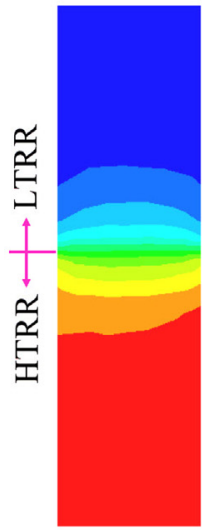

$y_{1}$

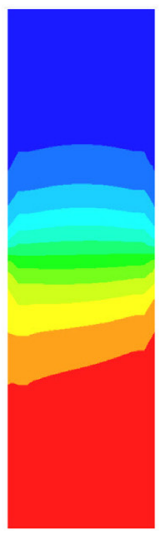

$y_{2}$

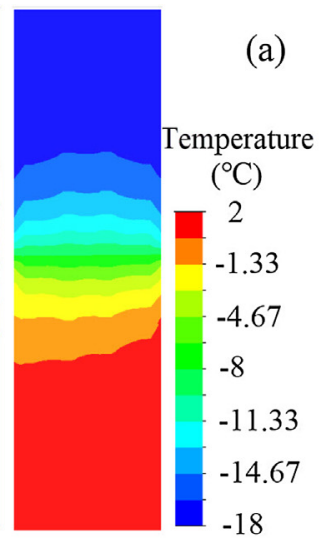

$y_{3}$

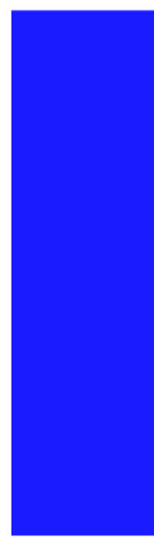

$y_{1}$

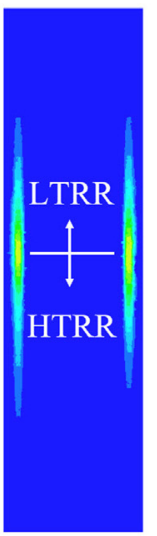

$y_{2}$

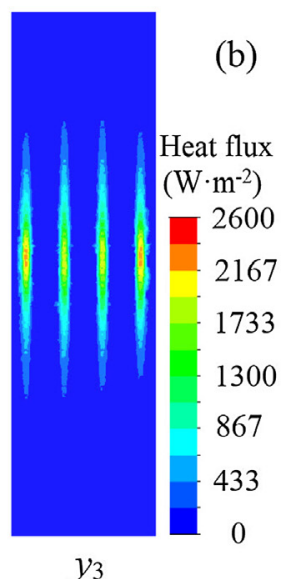

$y_{3}$

Fig. 3. (a) Temperature and (b) heat flux density contours for the thermal bridge from the HTRR to LTRR.
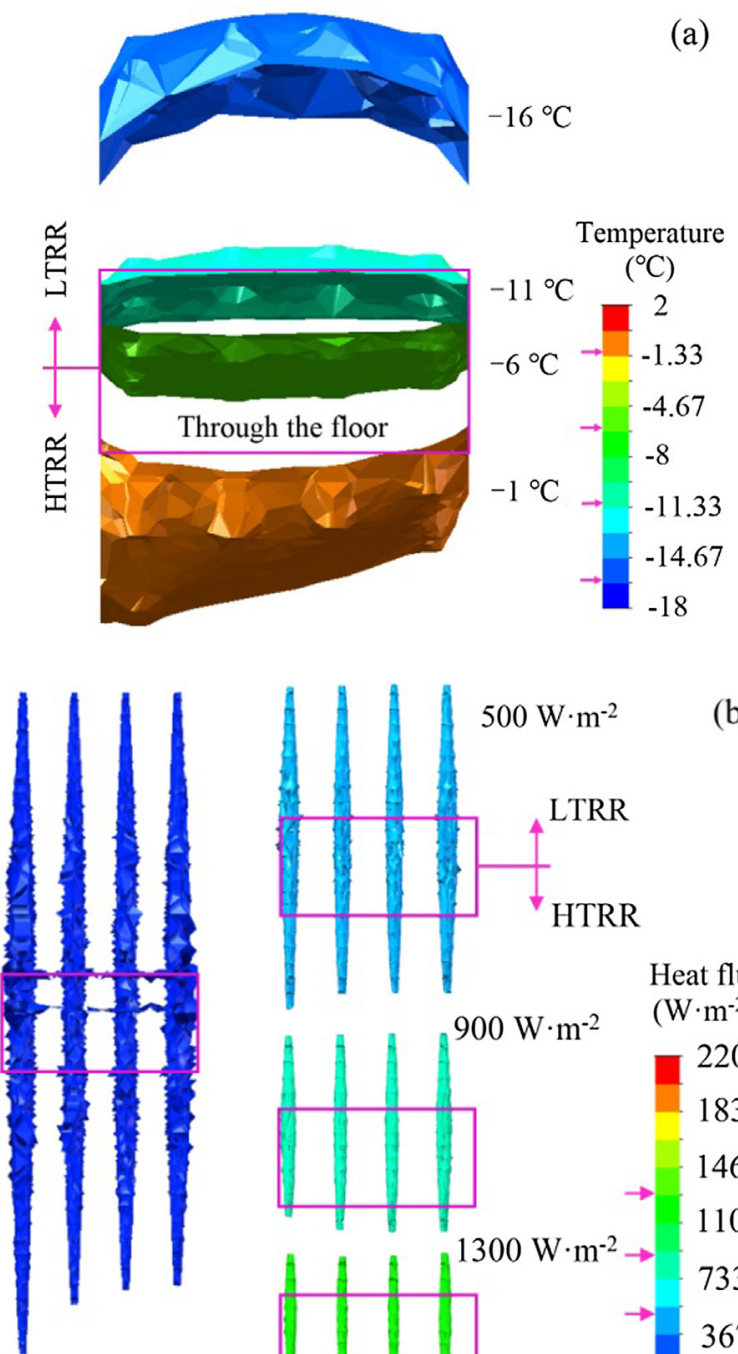

$100 \mathrm{~W} \cdot \mathrm{m}^{-2}$

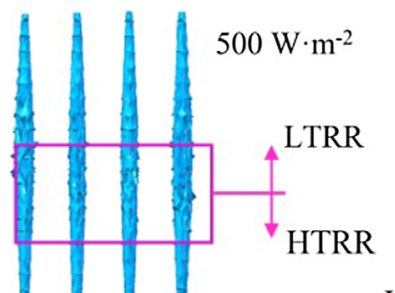

Heat flux $\left(\mathrm{W} \cdot \mathrm{m}^{-2}\right)$

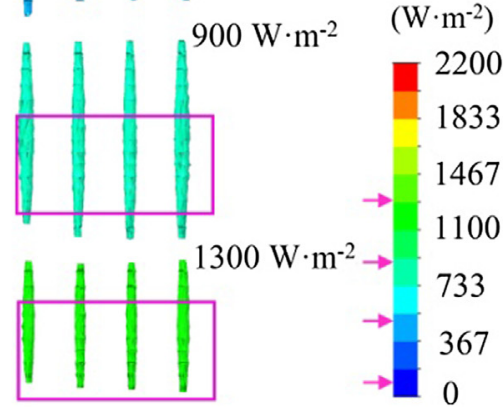

Fig. 4. (a) Isothermal contour temperatures and (b) iso-flux contours of the heat flux density for the thermal bridge from the HTRR to LTRR in the uninsulated column.

in the LTRR above a height of $1.25 \mathrm{~m}$. The errors in the wall temperature in the LTRR between the experimental data and simulation result are within about $\pm 2.46 \%$ (that is, the maximum error was only $1.55^{\circ} \mathrm{C}$ ) after considering the systematic errors $\left(-1.18^{\circ} \mathrm{C}\right)$. It can be concluded that the simulation results can reflect the actual temperature distribution of the column in the refrigeration room with an acceptable error rate. Thus, the simulation model of the thermal bridge of the column was reliable and of sufficient accuracy for the present study.

\section{Results and discussion}

\subsection{Thermal bridges of the uninsulated column}

It is necessary to investigate the heat transfer process in the columns of the thermal bridges with and without the addition of insulation materials on the column. The following section discusses the thermal transfer characteristics within the uninsulated columns, as shown in Fig. 3.

As depicted in Fig. 3, the locations at $y_{1}, y_{2}$, and $y_{3}$ represent the planes through zero, two, and four steel bars, respectively. Heat transfer by the thermal bridge centers around the upper and lower sides of the floor. In Fig. 3(a), the temperature difference is $6.73^{\circ} \mathrm{C}$, from -11.27 to $-18^{\circ} \mathrm{C}$, along with the column height above the floor, signifying an average rate of temperature change of $1.346^{\circ} \mathrm{C}$ per meter (i.e., $6.73^{\circ} \mathrm{C}$ / $5 \mathrm{~m}$ ) in the column in the LTRR. Below the floor, the temperature difference is $4.33^{\circ} \mathrm{C}$ from -2.33 to $2{ }^{\circ} \mathrm{C}$, denoting an average rate of temperature change of $0.866^{\circ} \mathrm{C}$ per meter (i.e., $4.33^{\circ} \mathrm{C} / 5 \mathrm{~m}$ ) in the column within the HTRR. It can be seen that the temperature in the uninsulated column drops rapidly on the LTRR side, and decreases slowly on the HTRR side, showing that the column temperature attenuates faster on the LTRR side. In Fig. 3b (locations in the $y_{2}$ and $y_{3}$ directions), since the thermal conductivity of the steel bars is large, a higher heat flux centers around the steel bar. This phenomenon results in a large amount of heat flux transferring from the HTRR to the LTRR. The maximum heat flux density is about $2313 \mathrm{~W} / \mathrm{m}^{2}$ in the steel bars. This heat flux decreases by $2093 \mathrm{~W} / \mathrm{m}^{2}$ from 2143 to $50 \mathrm{~W} / \mathrm{m}^{2}$ in the steel bar in the LTRR column, representing an average rate of flux density change of $418.6 \mathrm{~W} / \mathrm{m}^{2}$ per meter (i.e., $2093 \mathrm{~W} / \mathrm{m}^{2} / 5 \mathrm{~m}$ ). Moreover, the heat flux reduces by $1143 \mathrm{~W} / \mathrm{m}^{2}$ from 1193 to $50 \mathrm{~W} / \mathrm{m}^{2}$ in the steel bar of the HTRR column, signifying an average rate of flux density change of $228.6 \mathrm{~W} / \mathrm{m}^{2}$ per meter (i.e., $1143 \mathrm{~W} / \mathrm{m}^{2} / 5 \mathrm{~m}$ ). The decreasing temperature and heat flux on the LTRR side is much greater than that on the HTRR side. In addition, these phenomena substantiate the idea that the thermal bridge effect is susceptible to high thermal conductivity materials, and thermal transfer by the thermal bridge is marginal.

To gain a better understanding of thermal bridging through the uninsulated column, the isothermal contours for temperature and heat flux within the column at location $y_{3}$ are presented in Fig. 4. In Fig. 4(a), the isothermal values of -1 and $-6{ }^{\circ} \mathrm{C}$ temperatures in the column are 
concave toward the HTRR side, and those of -11 and $-16^{\circ} \mathrm{C}$ are convex toward the LTRR side. The isothermal contour varies from concave on the HTRR side to convex on the LTRR side due to the heat transfer effect from the thermal bridge in the column. In Fig. 4b, by comparison with the isothermal value of the 100, 500, 900, and $1300 \mathrm{~W} / \mathrm{m}^{2}$ heat flux, heat transfer in the column is mainly accomplished by the steel bars from the high temperature in the HTRR side to the low temperature in the LTRR side. Simultaneously, a large amount of heat is conducted by the steel bars in the column, resulting in the cooling loss (i.e., energy loss).

The surface temperature of the columns at location $y_{1}$ is close to or the same as the surrounding air temperature of the column within a short distance. From Figs. 3 and 4, it can be deduced that if the heat transfer (i.e., the amount of cooling loss) is to be reduced, heat preservation in the column on the LTRR side would be more effective than on the HTRR side. According to the building model and boundary conditions on the LTRR side, the cooling load entering from the HTRR to the LTRR side via the column is $q_{0}=30.23 \mathrm{~W}$ (here, neglecting the amount of heat transfer from the floor layer). It is necessary to emphasize that, although the cross-sectional area of a single steel bar only accounts for $0.19 \%$ of the total cross-sectional area of the column, the heat transfer for a single steel bar is about $1.408 \mathrm{~W}$ which accounts for $4.66 \%$ of the overall heat transfer. In particular, it can be concluded that the total thermal transmittances of the column and the non-reinforced area can be determined to be 6.616 and $14.994 \mathrm{~m}^{2} \mathrm{~K} \mathrm{~W}^{-1}$, respectively, representing a $55.88 \%$ decrease (here, $\left(14.994-6.616 \mathrm{~m}^{2} \mathrm{~K} \mathrm{~W}^{-1}\right) / 14.994 \mathrm{~m}^{2} \mathrm{~K} \mathrm{~W}^{-1}=55.58 \%$ ). This observation reveals that the share contributed by the steel bars can reduce the thermal transmittance by $55.58 \%$, indicating that the contributing role of the steel bars in the column to cooling loss cannot be ignored. For a refrigeration room facility operated year-round, the annual cooling loss can be calculated as $264.81 \mathrm{kWh}$. Thus, the addition of heat preservation to the LTRR column may be more effective at energy savings than such an addition to the HTRR column.

\subsection{Thermal bridges of the insulated column}

To reduce the cooling loss in a refrigeration room, it is necessary to take measures to decrease the energy loss generated by the thermal bridge. One effective measure to decrease the amount of heat transfer is to wrap an insulating material around the column. From the viewpoint of effectively reducing the heat transfer and the amount of heat insulating material, this would be related to the type of insulation material and the storage temperatures, which would determine the thickness $(\delta)$ and height $(h)$ of the insulation layer.

As proposed in Section 3.1, it is preferable to install the insulating layer around the column on the LTRR side. In this study, the LTRR column was wrapped with polystyrene insulation material. Fig. 5 gives the cooling loss $(q)$ in relation to the height of the insulation layer at $\delta=0.15 \mathrm{~m}$ as well as the thickness of the insulation layer at $h=1.25$ on the LTRR side. Clearly, the cooling loss gradually decreased as the height and thickness of the insulation layer increased. However, there are optimum sizes for both $h$ and $\lambda$ since the reduction in cooling loss is limited.

The equivalent height $l(h)$ and thickness $l(\delta)$ of the insulated column can be defined as:

$l(\varphi)=\varphi / l_{0}$

where $\varphi$ represents $h$ or $\delta$, and $l_{0}=0.5 \mathrm{~m}$ is the length of the side of the uninsulated column.

The efficiency of the cooling loss reduction is used to evaluate the effect of the insulation layer size, as shown in Eq. (10). If $l=0, \eta$ goes to zero; if $q$ is minimum, $\eta=1$.

$\eta(l)=\frac{q_{0}-q(l)}{q_{0}-q_{\min }} \times 100 \%$

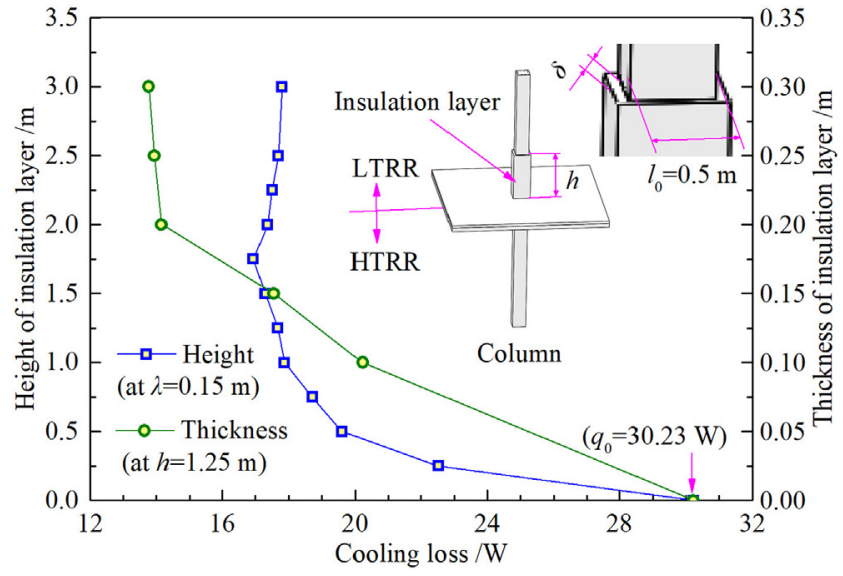

Fig. 5. The relation between cooling loss in the refrigeration room and both the height and thickness of the insulation layer.

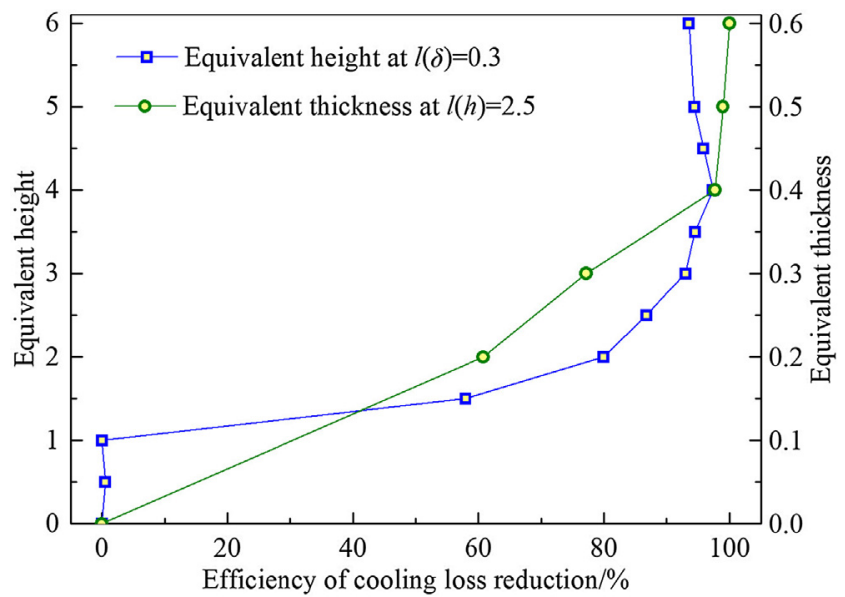

Fig. 6. Effect of equivalent sizes for the insulated column on the efficiency of the cooling loss reduction in the LTRR side.

Fig. 6 gives the relation between the efficiency of the reduction in cooling loss and the equivalent size of the insulated column. As depicted, $\eta(l)$ presents a significant increase to $94.51 \%$ as the equivalent height increases from 0 to $3.5 \mathrm{~m}$ at $l(\delta)=0.3$ (i.e., $\delta / l_{0}=0.15 \mathrm{~m} /$ $0.5 \mathrm{~m}$ ), signifying a decrease in the cooling loss from 30.23 to $16.94 \mathrm{~W}$. The $\eta(l)$ also increases to $97.69 \%$ as the equivalent thickness increases from 0 to 0.4 at $l(h)=2.5$ (i.e., $h / l_{0}=1.25 \mathrm{~m} / 0.5 \mathrm{~m}$ ), representing a reduction in the cooling loss from 30.23 to $14.16 \mathrm{~W}$. These phenomena can be explained by the increase in heat transfer resistance with consideration of the insulating material, resulting in a reduction in the heat transfer amount. However, the efficiency of the cooling loss reduction varies from $93.6 \%$ to $97.37 \%$ in the range of $l(h)=3.5-6$, and it varies from $97.69 \%$ to $100 \%$ in the range of $l(h)=3.5-6$, indicating that the cooling loss is reduced slowly in this range. An optimum equivalent size for the insulated column can be determined for minimizing cooling loss. The range of variation in the cooling loss is the largest in the range of both $l(h) \leq 1.25$ and $l(\delta) \leq 0.3$. Since the thicker insulation layer presents a higher cost for the refrigeration room, an optimum equivalent size for the insulated column for $l(h) \leq 1.25$ and $l(\delta) \leq 0.3$ is explored by comprehensively considering reducing both the heat transfer and the amount of heat-insulating material.

\subsection{Optimization of the energy-saving insulation method}

To minimize the thermal bridge through the columns in a refrigeration room, the relationship between cooling loss and insulation 
layer size is explored in order to obtain a better insulation technique. Hence, a binary quadratic empirical correlation for the cooling loss $(q)$ can be fitted as a function of the equivalent height and thickness in Eq. (11) according to Fig. 6.

$$
\begin{aligned}
q= & 1.6548 \cdot l(h)^{2}+195.2577 \cdot l(\delta)^{2}- \\
& 28.8019 \cdot l(h) \cdot l(\delta)-2.1024 \cdot l(h)- \\
& 77.8327 \cdot l(\delta)+30.23
\end{aligned}
$$

It is noted that the fitted correlation in Eq.11 can reach up to $97.87 \%$, representing a high accuracy. In addition, the cooling loss has a non-linear relationship with the insulation layer size.

When the amount of insulation material needed is too large, the operating costs saved may not be sufficient to cover the cost. Therefore, there is a need to determine the most economical solution for the amount of insulating materials needed. In this case, the insulation material is priced at RMB 800 per cubic meter, and the cost of electricity is RMB 1 per $\mathrm{kWh}$. Hence, the approximate cost of insulation material on the column is given as:

$s_{1} \approx 800 \cdot[l(h) \cdot l(\delta) \cdot 0.5 \cdot 4]=1600 \cdot l(h) \cdot l(\delta)$

Based on Eq. (11), if the service life of the insulation material in the refrigeration room is 20 years, and the refrigeration room is operated 365 days per year, $24 \mathrm{~h}$ a day, then the savings in cooling capacity $(Q$, unit: Wh) over 20 years can be calculated as:

$$
\begin{aligned}
Q & =\left(q_{0}-q\right) \times 24 \times 365 \times 20= \\
& -\left[1.6548 \cdot l(h)^{2}+195.2577 \cdot l(\delta)^{2}-\right. \\
& 28.8019 \cdot l(h) \cdot l(\delta)-2.1024 \cdot l(h)- \\
& 77.8327 \cdot l(\delta)] \times 24 \times 365 \times 20
\end{aligned}
$$

Since the refrigeration efficiency for a refrigerator room is generally lower than that for air conditioners, an energy efficiency ratio of 2 is assumed in the refrigeration system. Once the cooling loss is reduced, the electricity consumption saved ( $W$, unit: $\mathrm{kWh}$ ) can be defined as:

$W=\frac{Q}{2} \times \frac{1}{1000}$

If the electricity fee is RMB 1 per $\mathrm{kWh}$, then the savings in operating fees $\left(s_{2}\right)$ for 20 years can be calculated as:

$s_{2}=Q / 2000$

By subtracting the savings in operating costs from the cost of insulation material, the total cost savings $(\Delta s)$ for 20 years can be obtained from:

$\Delta s=s_{2}-s_{1}$

A relation between the total cost savings amount and the height and thickness of the insulation layer is presented in Fig. 9. As $\partial^{2} \Delta s / \partial^{2} l$ $(h)=-289.92<0$ and $\partial^{2} \Delta s / \partial^{2} l(\delta)=-34209.15<0$, the local optimal solution can be determined in Eq. (16). Here, this case ignores the appreciation or devaluation of money over 20 years. Using the optimization calculation in Eq. (14), the maximum total cost savings of $\Delta s=927.43$ (unit: RMB) at $l(h)=2.8$ and $l(\delta)=0.42$; that is, the most economical thermal insulation method can be obtained at $h=1.4 \mathrm{~m}$ and $\delta=0.21 \mathrm{~m}$.

To verify the accuracy of the most economical insulation method, three different insulation methods are randomly selected for comparison. As depicted in Fig. 7, the more insulation material that is used, the greater the cost savings are. In addition, for the same amount of insulation material, different insulation methods mean that the cooling loss is also different. The most economical insulation approaches not only use less insulation material, but they are also the most cost-effective for the entire operating cycle. The accuracy of the above ideas for finding the best solution can be substantiated.

For the best energy-savings insulation method, Fig. 8 gives the isothermal contours for temperature and heat flux inside the insulated column at the $y_{3}$ plane. When comparing Figs. 4(a) and 8(a), the

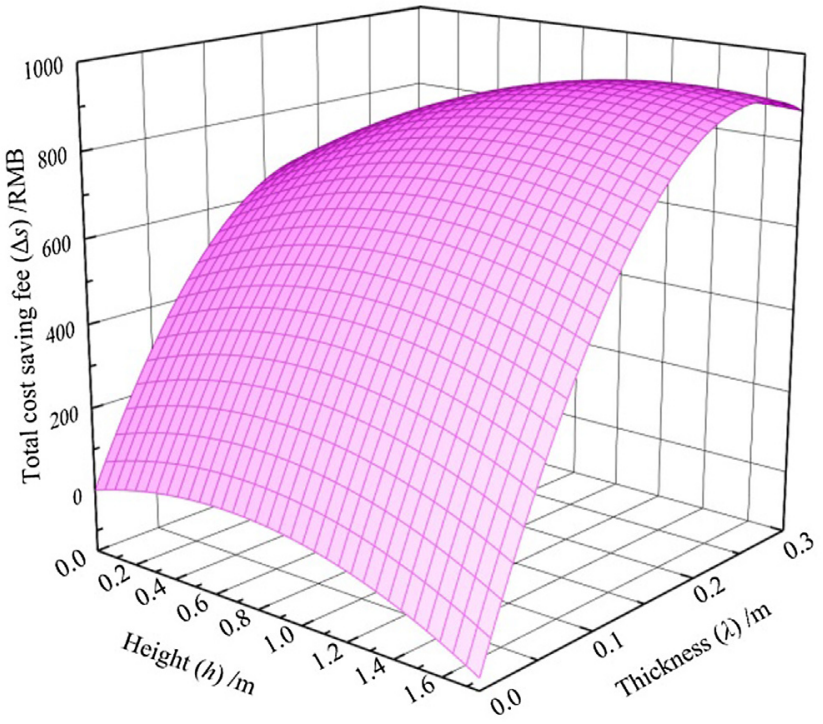

Fig. 7. Total cost savings at different insulation heights and thicknesses over 20 years.
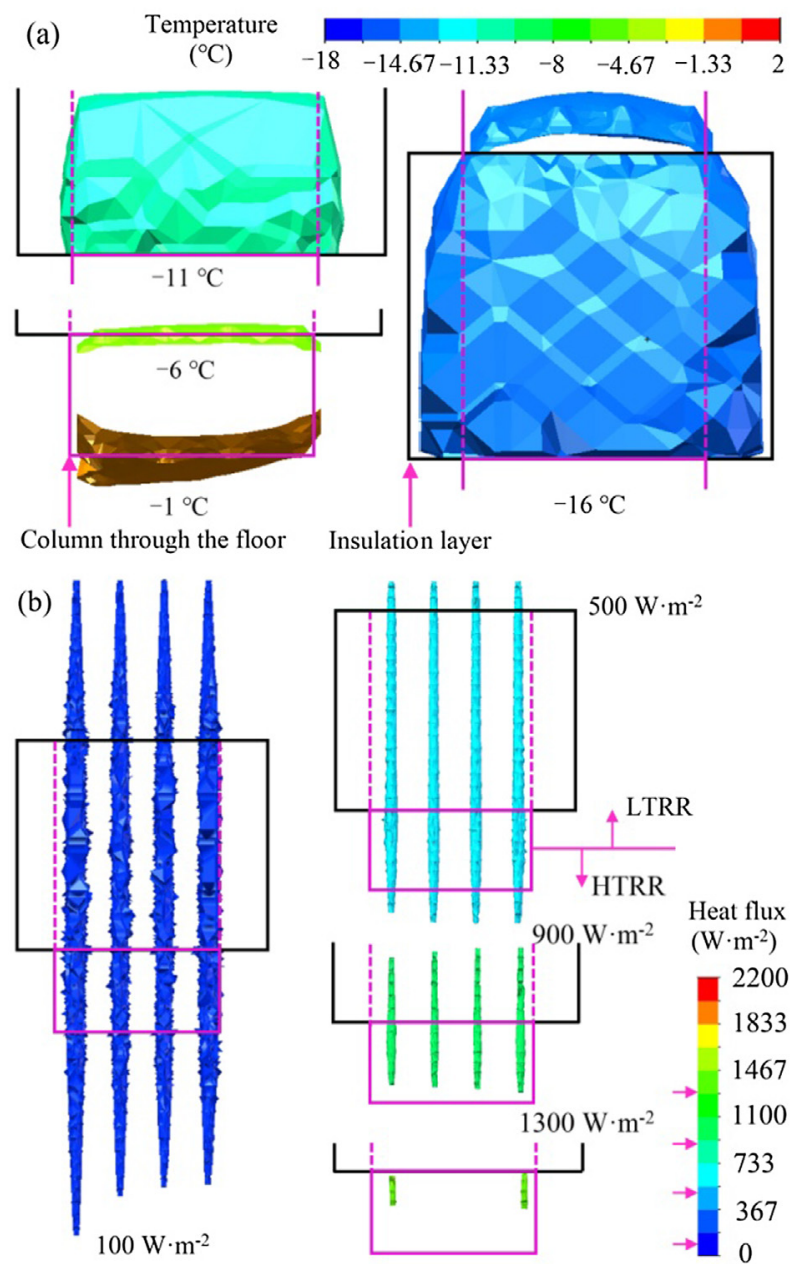

Fig. 8. Isothermal contours for (a) temperature and (b) heat flux in the insulated column from the HTRR to the LTRR.

volume of isothermal value for low temperature is larger and protrudes toward the LTRR side after adding the insulation layer. This phenomenon indicates that the temperature difference between the column 

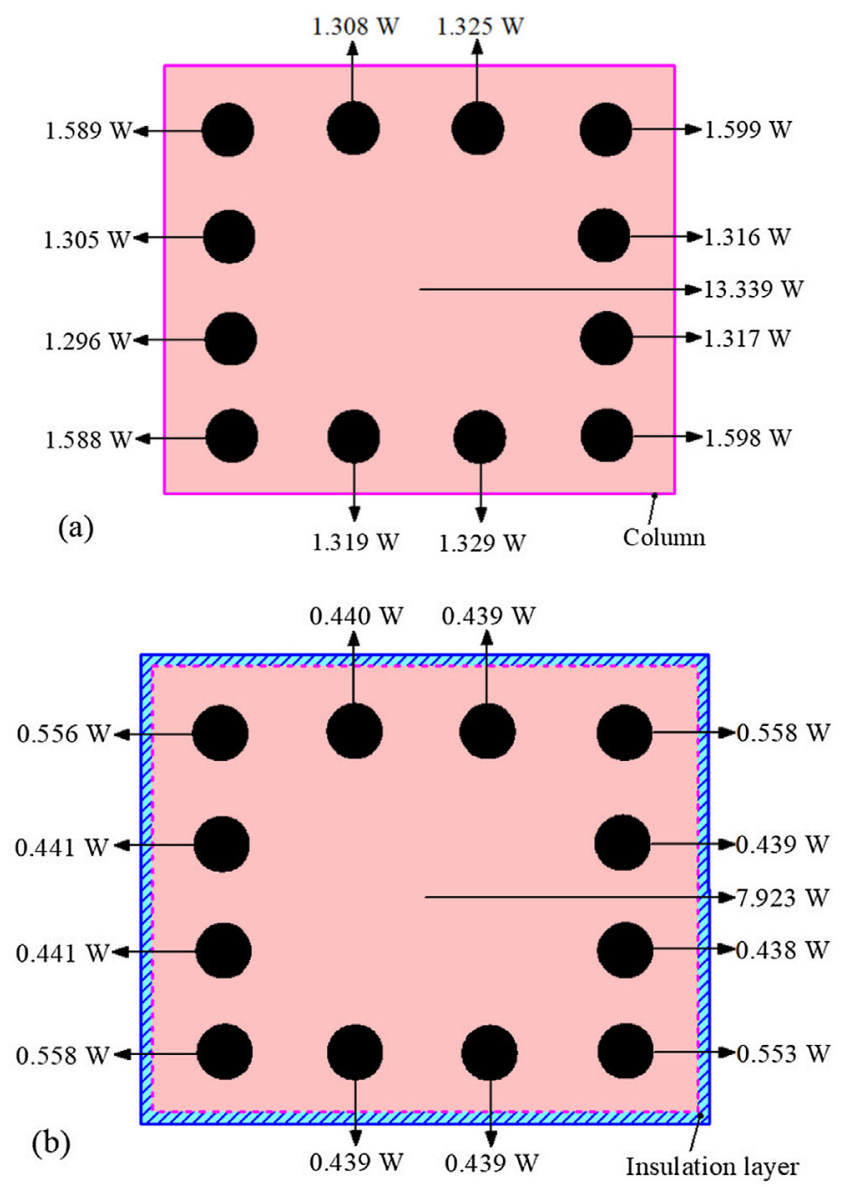

Fig. 9. Cooling loss distribution on the column section (a) without the insulation layer wrapped column, and (b) with the insulated column, at the most economical thermal insulation method.

surface and the surrounding air becomes small in the LTRR. When comparing Figs. 4(b) and 8(b), the maximum heat flux of $1848.45 \mathrm{~W} /$ $\mathrm{m}^{2}$ for the most economical insulation method is $37.34 \%$ lower than that of $2368.98 \mathrm{~W} / \mathrm{m}^{2}$ for the uninsulated method. Simultaneously, the isothermal density body is very small at a heat flux of $1300 \mathrm{~W} / \mathrm{m}^{2}$.

To compare the effect of thermal bridging with and without the insulation material wrapped around the column, Fig. 9 presents a comparative heat transfer through the cross-section of the column. As shown in the figure, the cooling loss of the non-reinforced area is $13.339 \mathrm{~W}$ in the uninsulated column and $7.923 \mathrm{~W}$ in the insulated column, representing a decrease in heat transfer of $40.6 \%$ due to the heat preservation scheme. Among the 12 steel bars, the heat transfer from the steel bars at the four corners of the column is the largest, and the average heat transfer for the most economical insulation method is $66 \%$ lower than that of the method without the insulation. It can be concluded that after adding the insulation layer, the total cooling loss decreases from 30.23 to $13.66 \mathrm{~W}$, representing a $54.81 \%$ reduction. The share of cooling loss contributed by the steel bars is $55.87 \%$ and $42.02 \%$, respectively, before and after heat preservation. Therefore, the method with insulation for the column can effectively reduce the cooling loss by thermal bridging.

In addition to setting up the HTRR beneath the LTRR, there are many other methods of preventing the soil from freezing under a lowtemperature refrigeration room, such as overhead ventilation and diffuse cooling methods. These methods are of interest for further study that would explore the energy loss and structural damage of thermal bridging to refrigeration buildings.

\section{Conclusions}

To reduce the energy consumption and operating costs in cold storage facilities, a cooling loss minimization method is worthy of study. This study takes the refrigeration room as an example to propose an optimal insulation scheme for the column that decreases the cooling loss. Then, the thermal bridge model is established to simulate the heat transfer process through the column from the high-temperature refrigeration room (HTRR) to the low-temperature refrigeration room (LTRR). The calculation accuracy of the numerical procedure is qualified by comparison with experimental data. A method to optimize heat preservation in the column is proposed to reduce the cooling loss. The main conclusions are summarized as follows:

The thermal bridge effect is susceptible to high thermal conductivity materials such as steel bars in this study, and thermal transfer is marginal by the thermal bridge. The share of cooling loss contributed by the steel bars and pure concrete are $42.02-55.87 \%$ and $44.13-57.98 \%$, respectively. Since the decreasing amount of temperature and heat flux in the LTRR side is much greater than that in the HTRR side, adding heat insulation onto the LTRR column is considered more effective for energy savings than adding it on the HTRR column.

The cooling loss has a non-linear relationship with the size of the insulation layer. After consideration of the insulation material wrapped around the LTRR column, the amount of heat flux can decrease by $37.34 \%$ relative to the uninsulated column, and the total cooling loss decreases from 30.23 to $13.66 \mathrm{~W}$, representing a $54.81 \%$ reduction. By optimizing the solution, the most economical thermal insulation method can be obtained with an insulation layer that is $1.4 \mathrm{~m}$ in height and $0.21 \mathrm{~m}$ thick to minimize cooling loss from the thermal bridge, signifying a maximum total cost savings amount of RMB 927.43 over 20 years. The insulation technique for the column can therefore effectively reduce the cooling loss from the thermal bridge.

\section{Declaration of Competing Interest}

We declare that we have no conflict of interest.

\section{Acknowledgement}

This work has been supported by the Leading project of science and technology plan of Fujian Province (Grant No: 2019H0029).

\section{Appendix A. Supplementary material}

Supplementary data to this article can be found online at https:// doi.org/10.1016/j.applthermaleng.2019.114565.

\section{References}

[1] J.M. Kearney, Changing food consumption patterns and their drivers, Encyclopedia Food Sec. Sustain. 2 (2019) 16-24.

[2] J.A. Evans, A.M. Foster, J.M. Huet, Specific energy consumption values for various refrigerated food cold stores, Energy Build. 74 (2014) 141-151.

[3] O. Laguerre, H.M. Hoang, D. Flick, Experimental investigation and modelling in the food cold chain: Thermal and quality evolution, Trends Food Sci. Technol. 29 (2013) 87-97.

[4] J.A. Evans, A.M. Foster, J.-M. Huet, L. Reinholdt, K. Fikiin, C. Zilio, et al., Specific energy consumption values for various refrigerated food cold stores, Energy Build. 74 (2014) 141-151.

[5] X.Q. Li, P.E. Campana, H.L. Li, J.Y. Yan, K. Zhu, Energy storage systems for refrigerated warehouses, Energy Procedia 143 (2017) 94-99.

[6] J.A. Evans, E.C. Hammond, A.J. Gigiel, A.M. Fostera, L. Reinholdt, K. Fikiin, C. Zilio, Assessment of methods to reduce the energy consumption of food cold stores, Appl. Therm. Eng. 62 (2014) 697-705.

[7] A.M. Foster, L.O. Reinholdt, T. Brown, Reducing energy consumption in cold stores using a freely available mathematical model, Sustain. Cities Soc. 21 (2016) 26-34.

[8] I. Garrido, S. Lagüela, P. Arias, Thermal-based analysis for the automatic detection and characterization of thermal bridges in buildings, Energy Build. 158 (2018) 1358-1367.

[9] A. Reilly, O. Kinnane, The impact of thermal mass on building energy consumption, Appl. Energy 198 (2017) 108-121. 
[10] Z.J. Liu, Y.W. Liu, B.J. He, Application and suitability analysis of the key technologies in nearly zero energy buildings in China, Renew. Sust. Energy Rev. 101 (2019) 329-345.

[11] X.Q. Jiang, H.M. He, X.Y. Li, Performance analysis and mixing ratio selection of mixed liquid desiccant for a dehumidification system, Indoor. Built Environ. (2019), https://doi.org/10.1177/1420326X19862009.

[12] X.H. Hao, Y.L. Ju, Simulation and anslysis on the flow field of the low temperature mini-type cold store, Heat Mass Transfer 47 (2011) 771-775.

[13] Hong-Minh Hoang, Steven Duret, Denis Flick, Preliminary study of airflow and heat transfer in a cold room filled with apple pallets: Comparison between two modelling approaches and experimental results, Appl. Therm. Eng. 46 (2014) 17-25.

[14] Rui Carneiro, P.D. Gaspar, P.D. Silva, 3D and transient numerical modelling of door opening and closing processes and its influence on thermal performance of cold rooms, Appl. Therm. Eng. 113 (2017) 585-600.

[15] Shen Tian, Yuping Gao, Shuangquan Shao, Development of an unsteady analytical model for predicting infiltration flow rate through the doorway of refrigerated rooms, Appl. Therm. Eng. 129 (2018) 179-186.

[16] J.R.D. Freitas, E.G.D. Cunha, Thermal bridges modeling in South Brazil climate: Three different approaches, Energy Build. 169 (2018) 271-282.

[17] S.A. Al-Sanea, M.F. Zedan, Effect of thermal bridges on transmission loads and thermal resistance of building walls under dynamic conditions, Appl. Energy 98 (2012) 584-593.

[18] G. Baldinelli, F. Bianchi, A. Rotili, A model for the improvement of thermal bridges quantitative assessment by infrared thermography, Appl. Energy 211 (2018) 854-864.

[19] Y.T. Ge, S.A. Tassou, Simulation of the performance of single jet air curtains for vertical refrigerated display cabinets, Appl. Therm. Eng. 21 (2001) 201-219.

[20] A. Capozzoli, A. Gorrino, V. Corrado, A building thermal bridges sensitivity analysis, Appl. Energy 107 (2013) 229-243.

[21] N.J. Smale, J. Moureh, G. Cortella, A review of numerical models of airflow in refrigerated food applications, Int. J. Refrig. 29 (2006) 911-930.

[22] A.Q. Lin, Q. Zheng, Y.T. Jiang, X. Lin, H. Zhang, Sensitivity of air/mist non-equilibrium phase transition cooling to transient characteristics in a compressor of gas turbine, Int J. Heat Mass Tran. 137 (2019) 882-894.

[23] F. Ascione, N. Bianco, R.F.D. Masi, Experimental validation of a numerical code by thin film heat flux sensors for the resolution of thermal bridges in dynamic conditions, Appl. Energy 124 (2014) 213-222.

[24] M. O'Grady, A.A. Lechowska, A.M. Hartea, Quantification of heat losses through building envelope thermal bridges influenced by wind velocity using the outdoor infrared thermography technique, Appl. Energy 208 (2017) 1038-1052.

[25] M. Ibrahim, P.H. Biwole, E. Wurtz, Limiting windows offset thermal bridge losses using a new insulating coating, Appl. Energy 123 (2014) 220-231.

[26] J. Prata, N. Simões, A. Tadeu, Heat transfer measurements of a linear thermal bridge in a wooden building corner, Energy Build. 158 (2018) 194-208.

[27] C. Carbonaro, S. Tedesco, F. Thiebat, S. Fantucci, V. Serra, M. Dutto, An integrated design approach to the development of a vegetal-based thermal plaster for the energy retrofit of buildings, Energy Build. 124 (2016) 46-59.

[28] L. Bianco, V. Serra, S. Fantucci, M. Dutto, M. Massolino, Thermal insulating plaster as a solution for refurbishing historic building envelopes: First experimental results, Energy Build. 95 (2015) 86-91.

[29] R. Galliano, K.G. Wakili, T. Stahl, B. Binder, B. Daniotti, Performance evaluation of aerogel-based and perlite-based prototyped insulations for internal thermal retrofitting: HMT model validation by monitoring at demo scale, Energy Build. 126 (2016) 75-86.

[30] Z.K. Cao, H. Han, B. Gu, A novel optimization strategy for the design of air curtains for open vertical refrigerated display cases, Appl. Therm. Eng. 31 (2011) 3098-3105.

[31] M.A. Delele, A. Schenk, E. Tijskens, H. Ramon, B.M. Nicolaï, P. Verboven, Optimization of the humidification of cold stores by pressurized water atomizers based on a multiscale CFD model, J. Food Eng. 91 (2009) 228-239.

[32] Code for design of cold store (English Version), Chinese Standard, 2010, No. GB 50072-2010.

[33] F. Attivissimo, A. Cataldo, L. Fabbiano, N. Giaquinto, Systematic errors and measurement uncertainty: An experimental approach, Measurement 44 (2011) 1781-1789. 